\title{
Production of solid fuel biochar from waste biomass by low temperature pyrolysis
}

\author{
Zhengang Liu ${ }^{\mathrm{a}, *}$, Guanghua Han ${ }^{\mathrm{b}}$ \\ ${ }^{a}$ Research Center for Eco-Environmental Sciences, Chinese Academy of Sciences, 18 Shuangqing Road, Beijing 100085, China \\ ${ }^{\mathrm{b}}$ Department of Industrial and Systems Engineering, National University of Singapore, Singapore 117576, Singapore
}

\section{H I G H L I G H T S}

- The biochars were produced from woody and non-woody biomass by pyrolysis.

- Woody biomass showed higher biochar and energy yields than non-woody biomass.

- Woody biomass showed lower decomposition rate than non-woody biomass.

- The biochars exhibited significantly improved combustion behaviors.

- Slagging and fouling issues were similar for raw biomass and biochars combustion.

\section{A R T I C L E I N F O}

\section{Article history:}

Received 28 September 2014

Received in revised form 11 May 2015

Accepted 15 May 2015

Available online 23 May 2015

\section{Keywords:}

Waste biomass

Pyrolysis

Biochar

Fuel quality

Combustion

\begin{abstract}
A B S T R A C T
Low temperature pyrolysis was employed to produce solid fuel biochars from woody (pine wood) and non-woody biomass (coconut fiber) in the present study. Chemical evolution of biomass under pyrolysis conditions was determined and fuel qualities of the biochars were evaluated including energy densities, ash-related problems and combustion behaviors. The results showed that dehydration reaction of the biomass had same preference with decarboxylation reaction under pyrolysis conditions. The hemicellulose and cellulose in non-woody biomass showed faster decomposition than those in woody biomass. The biochars derived from coconut fiber showed lower energy densities and energy yields than those from pine wood under identical conditions. All major ash forming metals originally contained in raw biomass were accumulated in the resultant biochars and more serious slagging and fouling problems were present during combustion of pyrolytic biochars compared to raw biomass. The reactivity of biomass decreased and the main mass loss shifted to elevated temperature zone with the increasing pyrolysis temperature, indicating increased thermal efficiency and environmental benefits were achievable during biochar combustion compared to raw biomass combustion. Taking into account combustion characteristics and energy yield, optimal pyrolysis temperatures for solid fuel production were around $300^{\circ} \mathrm{C}$ for coconut fiber and $330^{\circ} \mathrm{C}$ for pine wood.
\end{abstract}

(c) 2015 Elsevier Ltd. All rights reserved.

\section{Introduction}

The prospect of the exhaustion of fossil energy and climate change caused by the excessive use of fossil fuel necessitates shifting energy supply from fossil energy to renewable energy in the near future. Among all renewable energies, biomass energy is receiving increasing interests due to its wide availability worldwide [1]. Currently, biomass combustion alone or co-combustion with coal for heat and power generation in existing coal-fired systems is considered to be the lowest risk and least expensive

\footnotetext{
* Corresponding author. Tel./fax: +86 1062912718.

E-mail address: zgliu@rcees.ac.cn (Z. Liu).
}

strategy of combining utilization of biomass energy with substantial $\mathrm{CO}_{2}$ reduction in the atmosphere [2]. Unfortunately, raw biomass is not an ideal energy carrier and direct utilization of biomass faces great barriers originating from their inherent properties such as poor grindability, high moisture content and low energy density [3]. For example, poor grindability of biomass materials caused by its fibrous structure significantly increases energy consumption and creates a challenge during fuel preparation and feeding process. As for the high moisture content, it lowers the maximum combustion temperature and consequently could reduce the thermal efficiency and increase pollutant emissions [3]. To overcome these drawbacks, a pretreatment process is necessary to improve fuel quality of raw biomass prior to combustion. 
Pyrolysis has been employed to convert biomass feedstock into bio-fuels with high energy density, and biomass pyrolysis generates three product streams: liquid (bio-oil), gas, and solid product (biochar). The distributions and properties of these product streams are strongly dependent on pyrolysis conditions. Currently most attention is paid to the liquid and gaseous products, and many techniques and processes have been developed to increase the yield and improve the quality of these two target products [4-8]. However, due to the high instability and complex composition, bio-oil cannot be used directly, but requires further upgrading [4]. In the case of gaseous product, the low yield and complicated separation and purification processes limit its large-scale application in practice [8]. Under this situation, realizing high-value application of biochar can provide some advantages and a viable option to enhance biomass utilization efficiency.

Compared to liquid and gaseous products, only a few studies have been carried out with the aim of producing solid fuel biochars from waste biomass, and most of these studies focused on the improved physicochemical properties of woody biomass [9-16]. In contrast, limited studies are available for the biochars derived from most abundant agricultural wastes and there is a lack of information about the comparison of fuel qualities of the biochars from woody biomass and agricultural residue [10,13-16]. In addition, as we know, raw biomass combustion has low thermal efficiency and high pollutant emissions, and suffers from serious ash-related problems such as fouling and slagging problems [3]. However, combustion qualities and ash-related problems of pyrolytic biochars are scarcely studied in the literature although they are two key concerns for biomass used as solid fuel $[17,18]$.

In the present study, the biomass was pyrolyzed with the specific intention of solid fuel biochars production. Fuel quality of the biochars derived from woody and non-woody biomass was investigated including energy yield and combustion properties. Moreover, chemical evolution of the biomass under pyrolysis conditions was examined by FT-IR technique.

\section{Experimental}

\subsection{Materials}

Pine wood (PW) and coconut fiber (CF) were selected as representative woody and non-woody biomass, and their properties

Table 1

Properties of coconut fiber and pine wood used in the present study.

\begin{tabular}{lcc}
\hline Sample & Coconut fiber & Pine wood \\
\hline Ultimate analysis (daf, \%) & & \\
$\mathrm{C}$ & 47.75 & 48.15 \\
$\mathrm{H}$ & 5.61 & 6.70 \\
$\mathrm{~N}$ & 0.90 & 1.35 \\
$\mathrm{~S}$ & 0.23 & 0.20 \\
O (by difference) & 45.51 & 43.60 \\
Proximate analysis (db, \%) & & \\
Volatile matter & 80.85 & 85.45 \\
Fixed carbon & 11.10 & 13.15 \\
Ash & 8.05 & 1.40 \\
Major ash forming metals analysis & db, \%) \\
K & 1.600 & 0.105 \\
Ca & 0.329 & 0.198 \\
Na & 0.123 & 0.013 \\
Mg & 0.058 & 0.031 \\
Fe & 0.019 & 0.052 \\
Al & 0.005 & 0.018 \\
Ti & 0.007 & 0.062 \\
Si & 0.022 & 19.83 \\
HHV (dry, MJ/kg) & 19.23 & \\
\hline
\end{tabular}

- Not detected. were presented in Table 1 . PW and CF were dried at $60^{\circ} \mathrm{C}$ for $24 \mathrm{~h}$ prior to biochar production.

\subsection{Biochar preparation}

The pyrolysis of biomass was conducted in a fixed-bed quartz reactor equipped with a temperature controller. In every run, biomass sample was charged into an alumina boat which was then placed in a quartz tube. The furnace was heated to desired temperature $\left(200-330^{\circ} \mathrm{C}\right)$ with a heating rate $15^{\circ} \mathrm{C} / \mathrm{min}$ and kept at final temperature $20 \mathrm{~min}$ under argon gas atmosphere. After cooled down to room temperature, the biochar in alumina boat was weighted and kept in a desiccator for the analysis. The biochars derived from CF and PW were designated as "CF-Xxx" and "PW-xxx", where " $\mathrm{xxx}$ " shows pyrolysis centigrade temperature. Fig. 1 shows the images of several typical biochars prepared in the present study.

\subsection{Characterization}

The carbon, hydrogen, nitrogen and sulfur contents were determined on an EA3000 Elemental Analyzer (Italy). The higher heating value (HHV) of the fuel was measured with a Kaiyuan 5E-KC5410 Express Calorimeter (China). The infrared spectrum (as $\mathrm{KBr}$ disk) was recorded in the wavenumber range of $4000-400 \mathrm{~cm}^{-1}$ with a Nicolet Nexus 670 Spectrophotometer (USA) at room temperature. The fuel ash was prepared at $575{ }^{\circ} \mathrm{C}$ according to standard test method for ash in biomass (ASTM D 1102). As for the major ash forming metal (K, Na, Ca, Mg, Ti, Si, Fe and $\mathrm{Al}$ ) content determination, the fuel/ash was firstly digested in a mix of acids and hydrogen peroxide $\left(\mathrm{HNO}_{3}+\mathrm{H}_{2} \mathrm{SO}_{4}+\mathrm{HF}+\mathrm{H}_{2} \mathrm{O}_{2}\right)$ at $180{ }^{\circ} \mathrm{C}$ for $30 \mathrm{~min}$ using a Hanon microwave digester (China). The digestion solutions were then evaporated to dryness to remove the fluorides and the resultant residues were dissolved in $1: 1 \mathrm{HNO}_{3}$ solutions, followed by dilution by de-ionized water to desired volume. Subsequently the metal concentrations in the solution were quantified by ICP-OES Perkin Elmer Optima 3000 DV (USA). The metal oxide content was calculated according to corresponding metal content in ash.

Combustion analysis was conducted on a differential thermogravimetric analyzer TGA-7 (Perkin Elmer, USA). The fuel sample was heated from room temperature to final $700{ }^{\circ} \mathrm{C}$ at a linear heating rate of $20^{\circ} \mathrm{C} / \mathrm{min}$ under air flow rate of $30 \mathrm{ml} / \mathrm{min}$. In order to eliminate mass and heat transfer effects, very small sample sizes (around $5 \mathrm{mg}$ ) were loaded into an alumina crucible. To ensure the reproducibility, three replicates of each TGA experiment were performed.

\section{Results and discussion}

\subsection{Ultimate analysis, proximate analysis and major ash forming metal content analysis}

As shown in Table 2, carbon contents increase and oxygen contents decrease in the biochars with increasing pyrolysis temperature, indicating increased energy densities of the biochars. In contrast, there is no obvious change for nitrogen and sulfur contents in the biochars with the increasing temperatures and their values are lower than those of lignite. The lower contents of nitrogen and sulfur in biochars imply that like raw biomass combustion, similar environmental benefits can be achieved from the combustion of the biochars. Fig. 2 shows the removal degrees of carbon and hydrogen at different temperatures and it is evident that woody biomass PW underwent lower remove rates of hydrogen and carbon than non-woody CF at identical pyrolysis conditions. 


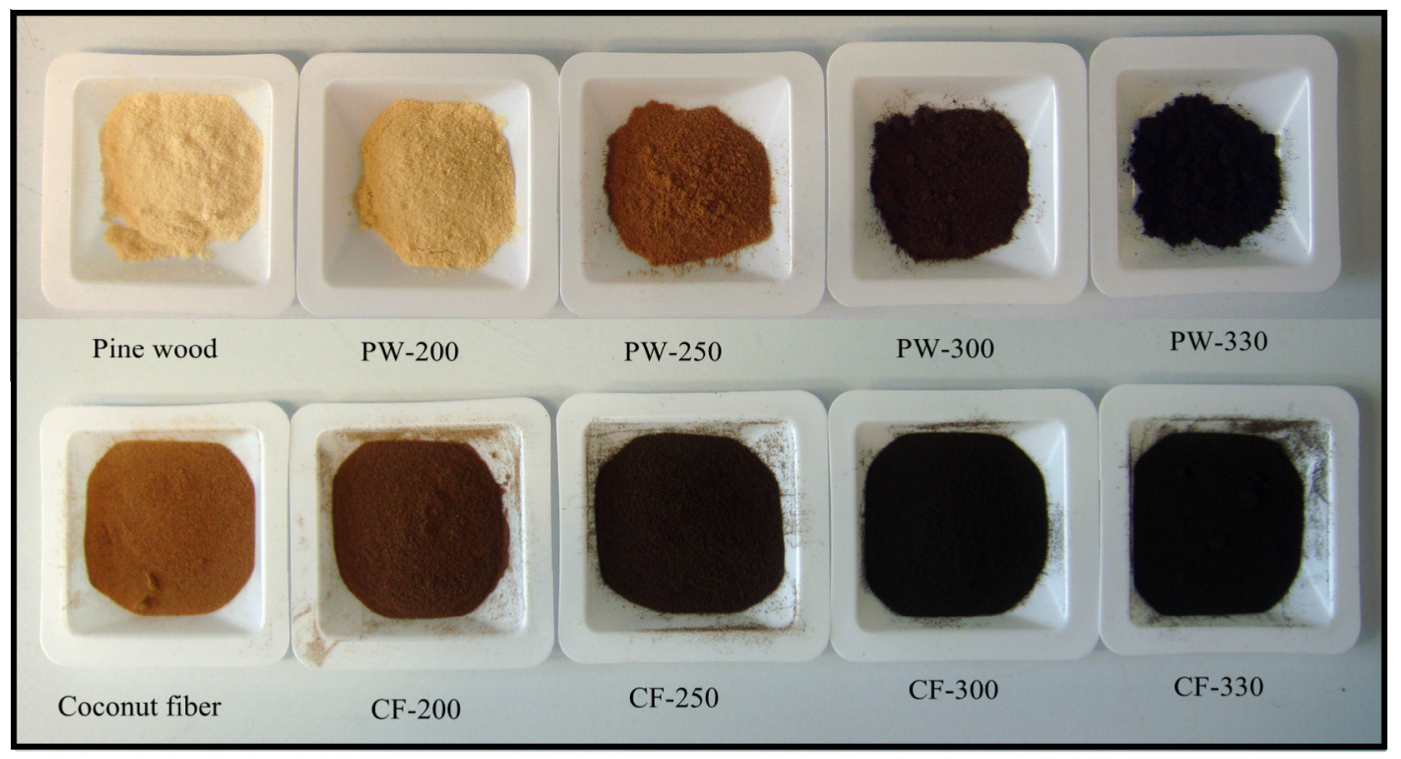

Fig. 1. Images of biochars prepared in the present study.

Table 2

Ultimate analysis, proximate analysis and energy analysis of the biochars derived from coconut fiber and pine wood.

\begin{tabular}{|c|c|c|c|c|c|c|c|c|c|c|c|}
\hline \multirow[t]{2}{*}{ Sample } & \multicolumn{3}{|c|}{ Proximate analysis (db, \%) } & \multicolumn{6}{|c|}{ Ultimate analysis (daf, \%) } & \multicolumn{2}{|c|}{ Energy analysis } \\
\hline & Volatile matter & Fixed carbon & Ash & $\mathrm{N}$ & $\mathrm{C}$ & $\mathrm{H}$ & $\mathrm{S}$ & $\mathrm{O}^{\mathrm{a}}$ & Biochar yield (\%) & HHV (MJ/kg) & Energy yield (\%) \\
\hline CF-200 & 78.26 & 15.04 & 6.70 & 1.35 & 50.42 & 5.20 & 0.45 & 42.58 & 83.11 & 19.93 & 87.5 \\
\hline CF-225 & 76.98 & 15.90 & 7.12 & 1.02 & 51.83 & 4.99 & 0.30 & 41.86 & 80.13 & 20.36 & 81.9 \\
\hline CF-250 & 75.58 & 16.37 & 8.05 & 1.13 & 53.77 & 4.76 & 0.28 & 40.06 & 69.19 & 21.03 & 71.5 \\
\hline CF-275 & 70.20 & 21.04 & 8.76 & 1.12 & 58.08 & 4.55 & 0.28 & 35.97 & 63.87 & 22.63 & 68.7 \\
\hline CF-300 & 64.21 & 25.71 & 10.08 & 1.21 & 61.38 & 4.08 & 0.32 & 33.01 & 55.65 & 23.80 & 58.5 \\
\hline CF-330 & 60.64 & 28.38 & 10.98 & 1.18 & 65.36 & 4.12 & 0.29 & 29.05 & 50.21 & 25.36 & 53.5 \\
\hline PW-200 & 80.43 & 18.62 & 0.95 & 1.33 & 51.16 & 6.54 & 0.18 & 40.79 & 91.00 & 20.74 & 99.8 \\
\hline PW-225 & 78.25 & 20.77 & 0.98 & 1.34 & 51.74 & 6.50 & 0.17 & 40.25 & 89.17 & 20.00 & 90.3 \\
\hline PW-250 & 75.84 & 23.09 & 1.07 & 1.34 & 52.00 & 6.35 & 0.17 & 40.14 & 79.19 & 21.06 & 79.4 \\
\hline PW-275 & 70.33 & 28.51 & 1.16 & 1.65 & 53.37 & 6.20 & 0.18 & 38.60 & 72.00 & 21.66 & 74.1 \\
\hline PW-300 & 58.34 & 40.37 & 1.29 & 1.68 & 55.52 & 6.07 & 0.22 & 36.51 & 65.16 & 22.60 & 68.0 \\
\hline PW-330 & 50.71 & 47.90 & 1.39 & 1.60 & 59.86 & 5.81 & 0.20 & 32.53 & 61.42 & 24.49 & 63.3 \\
\hline Lignite & 48.76 & 40.98 & 10.26 & 1.74 & 61.64 & 5.72 & 0.77 & 30.13 & - & 25.31 & - \\
\hline
\end{tabular}

- Not available.

a By difference.

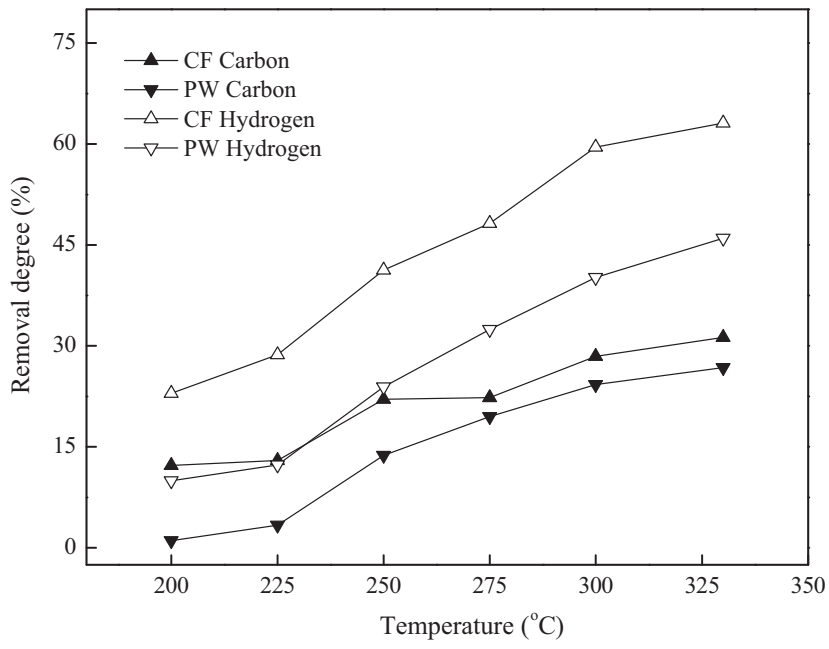

Fig. 2. Removal degrees of carbon and hydrogen in coconut fiber and pine wood as a function of pyrolysis temperature.

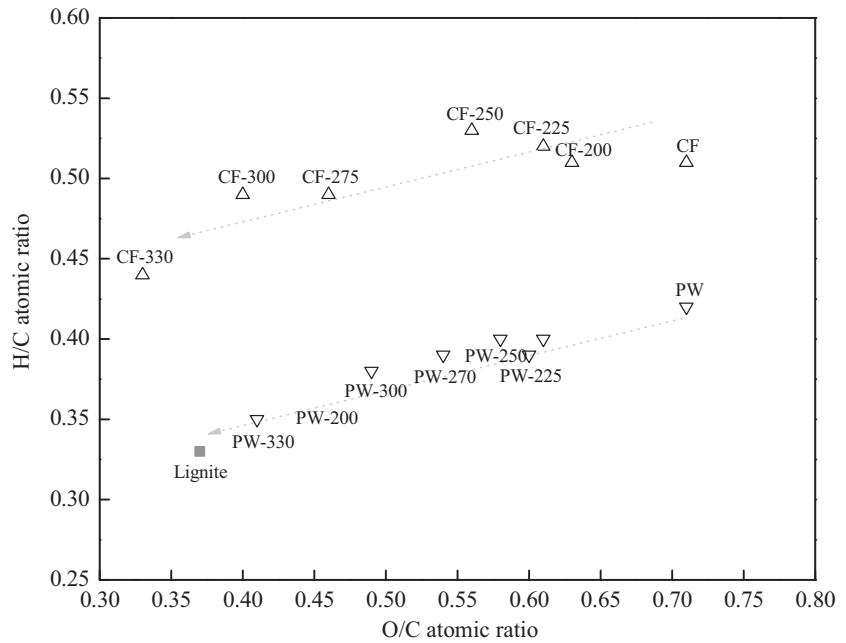

Fig. 3. Atomic $\mathrm{H} / \mathrm{C}$ and $\mathrm{O} / \mathrm{C}$ ratios of coconut fiber, pine wood and their derived biochars (lignite for comparison). 

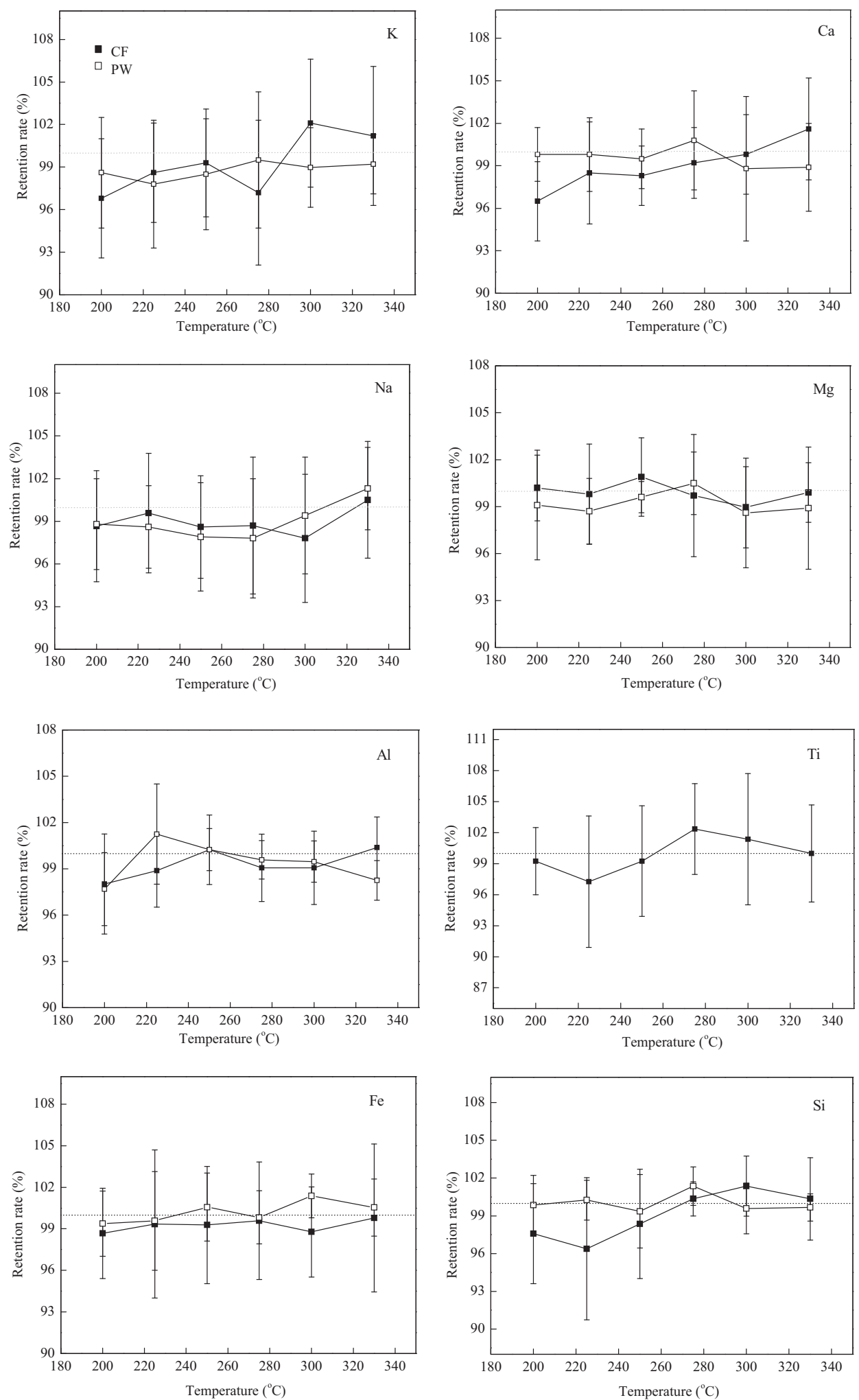

Fig. 4. Retention rates of major ash forming metals during pyrolysis of coconut fiber and pine wood.

The removal degree of hydrogen is nearly two times higher than that of carbon in both CF and PW with the exception of PW pyrolysis at 200 and $250^{\circ} \mathrm{C}$. As we know, the hydrogen and carbon in biomass are removed mainly through dehydration and decarboxylation reactions, respectively. Considering co-occurrence of demethanation reaction, removal degrees of carbon and hydrogen indicate that decarboxylation reaction has similar preference to de-hydration under low temperature pyrolysis. In addition, the variation in elemental composition of the biochars was also analyzed via a van Krevelen diagram as illustrated in Fig. 3. It can be seen that only the biochar obtained at $330^{\circ} \mathrm{C}$ pyrolysis has similar atomic composition to that of the lignite. Besides low temperature 

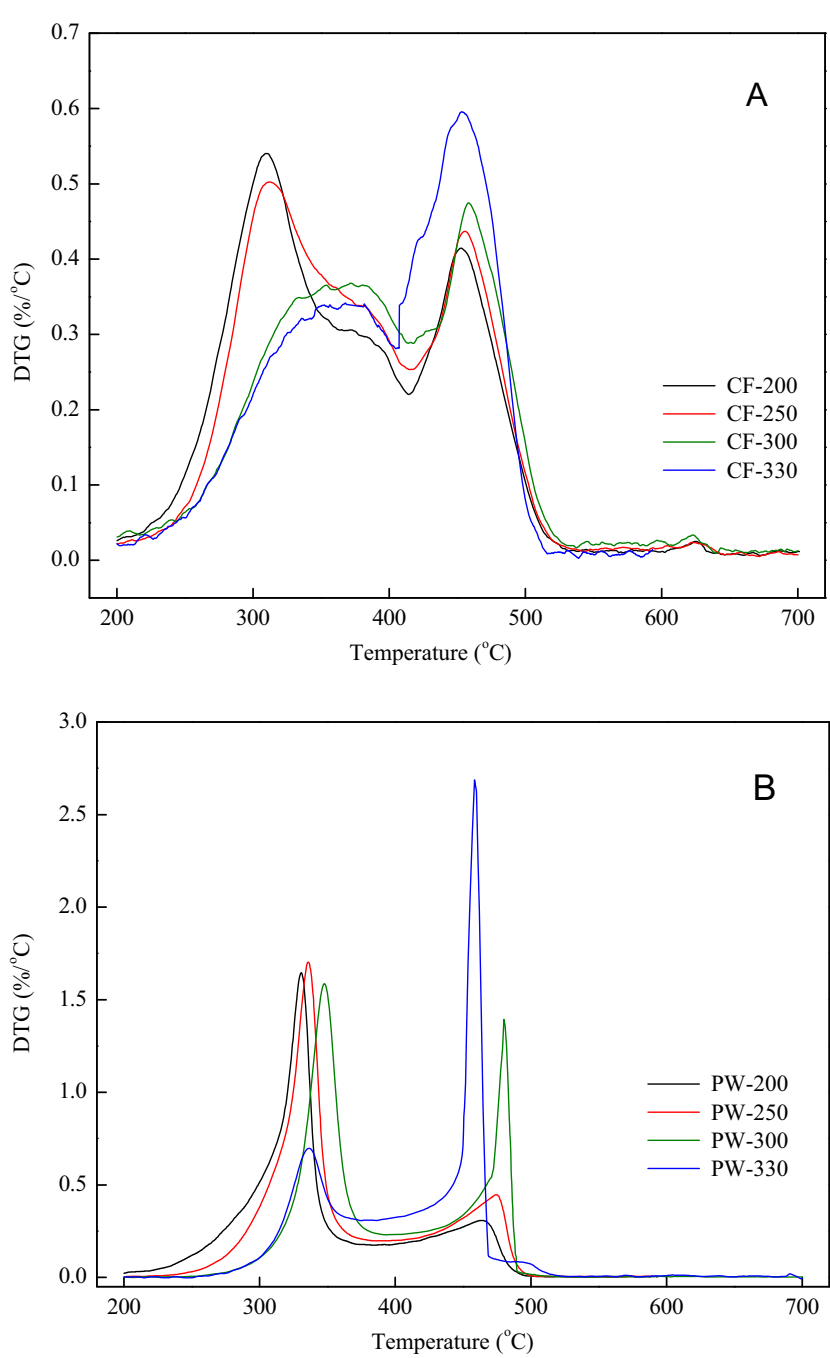

Fig. 5. DTG curves for the combustion of pyrolytic biochars derived from coconut fiber and pine wood.

pyrolysis, hydrothermal carbonization has also been employed to biomass upgrading and it was reported that the biochar produced from hydrothermal carbonization at $250^{\circ} \mathrm{C}$ have similar compositions to that of lignite [9]. The difference between pyrolytic biochar and hydrothermal biochar reveals that the biomass underwent a less decomposition/carbonization degree under pyrolysis conditions compared to hydrothermal carbonization at same temperature [19].

Fuel ratio is a ratio of fixed carbon against volatile matter and is a characteristic value representing the property of a solid fuel and classifying coal rank according to ASTM 388. As shown in Table 2, the volatile matter contents in biochars decrease and fixed carbon contents increase with the increasing pyrolysis temperature. Therefore, fuel ratios of the biochars increase with the increasing temperature, especially at the temperatures higher than $275^{\circ} \mathrm{C}$. The increased fuel ratios imply elevated combustion efficiencies and reduced pollutant emissions during biochars combustion compared to raw biomass combustion. Despite increased HHVs, the energy yields decrease with the increasing temperature due to the significantly decreased mass yields of the biochars. In comparison to non-woody biomass CF, woody PW has higher mass and energy yields under identical pyrolysis conditions. For CF, there is a significant decrease for energy yield when the temperature increases from 275 to $300^{\circ} \mathrm{C}$. While in the case of PW, the remarkable decrease is observed when the temperature increases from 300 to $330^{\circ} \mathrm{C}$.

To determine ash-related problems during biochar combustion, the fate of major ash forming metals in raw biomass were investigated during pyrolysis upgrading. The retention rate is defined as percentage of the mass content in the biochar relative to those contained in parent biomass and Fig. 4 presents the retention rates of major ash forming metals at different temperatures. Within tested temperatures, all major ash forming metals are totally remained in resultant biochars. As for the fate of metals during biomass pyrolysis, only several papers are available in the literature [20]. For example, it was reported that $\mathrm{K}$ and $\mathrm{Na}$ started to release around $400{ }^{\circ} \mathrm{C}$, and $\mathrm{Ca}$ and $\mathrm{Mg}$ around $600{ }^{\circ} \mathrm{C}$ for pine sawdust pyrolysis in a wire-mesh reactor [20]. The results obtained in the present study are well consistent with previous reports and the $100 \%$ retention rates possibly are related to the low volatilization rate due to the low heating rate and low pyrolysis temperature. It is worthy to note that metal retention rate $s$ are different under pyrolysis and hydrothermal carbonization conditions, and most of alkali and alkaline earth metals (AAEMs) and high fraction of heavy metals are removed in hydrothermal biochars [19].

The slagging and fouling inclination during biochar combustion are indicated as the values calculated by the follows equations [21]:

Slagging index $(\mathrm{SI})=(B / A) \times S \%$

Fouling index $(\mathrm{FI})=(B / A) \times\left(\mathrm{Na}_{2} \mathrm{O}+\mathrm{K}_{2} \mathrm{O}\right)$

where $B / A=\left(\mathrm{Fe}_{2} \mathrm{O}_{3}+\mathrm{CaO}+\mathrm{MgO}+\mathrm{Na}_{2} \mathrm{O}+\mathrm{K}_{2} \mathrm{O}\right) /\left(\mathrm{SiO}_{2}+\mathrm{Al}_{2} \mathrm{O}_{3}+\mathrm{TiO}_{2}\right)$; $S$ is the percent of the sulfur in dry fuel sample.

The $100 \%$ retention rates of major ash forming metals and comparable sulfur contents suggest that more serious slagging and fouling issues are expected during biochar combustion compared to raw biomass combustion. The calculated slagging and fouling indices according to Eqs. (1) and (2) also confirm that the slagging and fouling inclinations increase with increasing pyrolysis temperature and the biochars have increased SI and FI values than raw biomass generally (major metal oxides content in the ash and SI and FI values of raw biomass and the biochars are shown in

Table 3

Combustion parameters of the biochars derived from coconut fiber and pine wood.

\begin{tabular}{|c|c|c|c|c|c|c|c|c|c|}
\hline & \multicolumn{2}{|c|}{ Temperature interval $\left({ }^{\circ} \mathrm{C}\right)$} & \multicolumn{2}{|c|}{ Mass loss (\%) } & \multicolumn{2}{|c|}{ Peak temperature $\left({ }^{\circ} \mathrm{C}\right)$} & \multicolumn{2}{|c|}{$\mathrm{DTG}_{\max }\left(\% /{ }^{\circ} \mathrm{C}\right)$} & \multirow[t]{2}{*}{ Residue (\%) } \\
\hline & Stage I & Stage II & Stage I & Stage II & Stage I & Stage II & Stage I & Stage II & \\
\hline CF-200 & $264-412$ & $412-500$ & 53.31 & 25.28 & 309 & 454 & 0.54 & 0.42 & 8.64 \\
\hline CF-250 & $270-415$ & $415-505$ & 52.51 & 34.41 & 312 & 455 & 0.50 & 0.44 & 10.26 \\
\hline CF-300 & $282-416$ & $416-500$ & 44.44 & 39.81 & 370 & 459 & 0.37 & 0.56 & 12.29 \\
\hline CF-330 & $281-405$ & $405-490$ & 42.86 & 39.47 & 367 & 453 & 0.40 & 0.60 & 13.99 \\
\hline PW-200 & $301-385$ & $385-480$ & 51.47 & 22.00 & 331 & 464 & 1.71 & 0.32 & 2.56 \\
\hline PW-250 & $314-391$ & $391-484$ & 58.76 & 26.34 & 336 & 473 & 1.70 & 0.44 & 3.12 \\
\hline PW-300 & $328-402$ & $402-486$ & 47.82 & 35.96 & 346 & 480 & 1.58 & 1.38 & 3.80 \\
\hline PW-330 & $326-381$ & $381-472$ & 29.11 & 56.66 & 337 & 458 & 0.69 & 2.66 & 3.95 \\
\hline
\end{tabular}


Supplementary Material). Considering lower ash content in PW derived biochars together with higher energy yields and lower slagging and fouling inclinations, woody biomass are more suitable for biochar production than agricultural biomass.

\subsection{Combustion behavior of pyrolytic biochar}

DTG profiles depicting the combustion process of the pyrolytic biochars derived from $\mathrm{CF}$ and PW are present in Fig. 5. The characteristic temperatures and peak points of the combustion process are summarized in Table 3.

The biochars derived from CF and PW exhibit different combustion patterns and in general, each biochar shows two main mass loss peaks in DTG curves.

Two overlap combustion peaks are present in all the biochars derived from CF. With the increasing pyrolysis temperatures, the maximum mass loss rate (DTG $\mathrm{Dax}_{\max }$ ) and main mass loss of the biochars decrease within the low temperature range and shift to high combustion temperature range. For example, mass losses within low and high temperature range are $53.31 \%$ and $25.28 \%$ for CF-200, and $42.86 \%$ and $39.47 \%$ for CF-330, respectively. As for the $\mathrm{DTG}_{\max }$ in low and high temperature ranges, their values of $\mathrm{CF}-200$ are $0.54 \% /{ }^{\circ} \mathrm{C}$ and $0.42 \% /{ }^{\circ} \mathrm{C}$ and for $\mathrm{CF}-330$, they are $0.40 \% /{ }^{\circ} \mathrm{C}$ and $0.60 \% /{ }^{\circ} \mathrm{C}$, respectively. In comparison to $\mathrm{CF}$ derived biochars, two more separated sharp peaks were present in DTG curves of PW derived biochars. Like the biochars derived from $\mathrm{CF}$, same trend was observed for PW derived biochars with increasing temperature: decreased $\mathrm{DTG}_{\max }$ of low temperature range and increased mass loss within high temperature range. For PW-200, a sharp DTG peak was observed centered at $331{ }^{\circ} \mathrm{C}$ and a mass loss of $51.47 \%$ was measured within the temperature range of 385$480{ }^{\circ} \mathrm{C}$. The second peak centered at $464^{\circ} \mathrm{C}$ and the mass loss within the temperature range of $385-480{ }^{\circ} \mathrm{C}$ was around $22.00 \%$. With the increasing pyrolysis temperature, DTG $\mathrm{max}_{\max }$ decreased in the low combustion range and increased in high temperature range. For example, $\mathrm{DTG}_{\max }$ of low and high temperature ranges were $1.70 \% /{ }^{\circ} \mathrm{C}$ and $0.44 \% /{ }^{\circ} \mathrm{C}$ for $\mathrm{PW}-250$, and $0.69 \% /{ }^{\circ} \mathrm{C}$ and $2.66 \% /{ }^{\circ} \mathrm{C}$ for $\mathrm{PW}-330$, respectively. The decreased $\mathrm{DTG}_{\max }$ and increased temperature range for main mass loss suggests the reactivities of the biochars decrease with increasing pyrolysis temperatures. In addition, the decreased volatiles content of the biochars is also consistent with the decreased reactivities (shown in Table 2). It is well known that low combustion temperature of raw biomass due to their high reactivity results in low thermal efficiency and high pollutant emissions [3]. Therefore, the decreased reactivity indicates that high energy recovery efficiency and environmental benefits can be achieved by biochar combustion. As a comparison, pyrolytic biochars have higher reactivities than hydrothermal biochars, and the higher reactivities are ascribed to the catalytic effect of AAEM originally contained in raw biomass [22]. As aforementioned, AAEMs are accumulated in pyrolytic biochar while they are largely removed in hydrothermal biochars [23].

In addition, it can be seen that there is significant improvement for the combustion property of the biochar when pyrolysis temperature increase from 300 to $330^{\circ} \mathrm{C}$ for PW and from 250 to 300 for $\mathrm{CF}$, respectively. Previous studies showed that the temperature played significant role in biomass upgrading and in general the temperature range of $200-300^{\circ} \mathrm{C}$ was suggested to produce solid fuel biochar from biomass $[10,12,15]$. In the present study, it was shown that woody biomass PW should be pyrolyzed at higher temperature than agricultural waste $\mathrm{CF}$ to obtain better combustion efficiency. Taking into account of energy yield, the suitable pyrolysis temperatures for the production of solid fuel are around $330^{\circ} \mathrm{C}$ for PW and around $300^{\circ} \mathrm{C}$ for $\mathrm{CF}$, respectively. This conclusion is well supported by a previous report that the pyrolysis performed at $200-300{ }^{\circ} \mathrm{C}$ cannot improve the combustion property of biomass
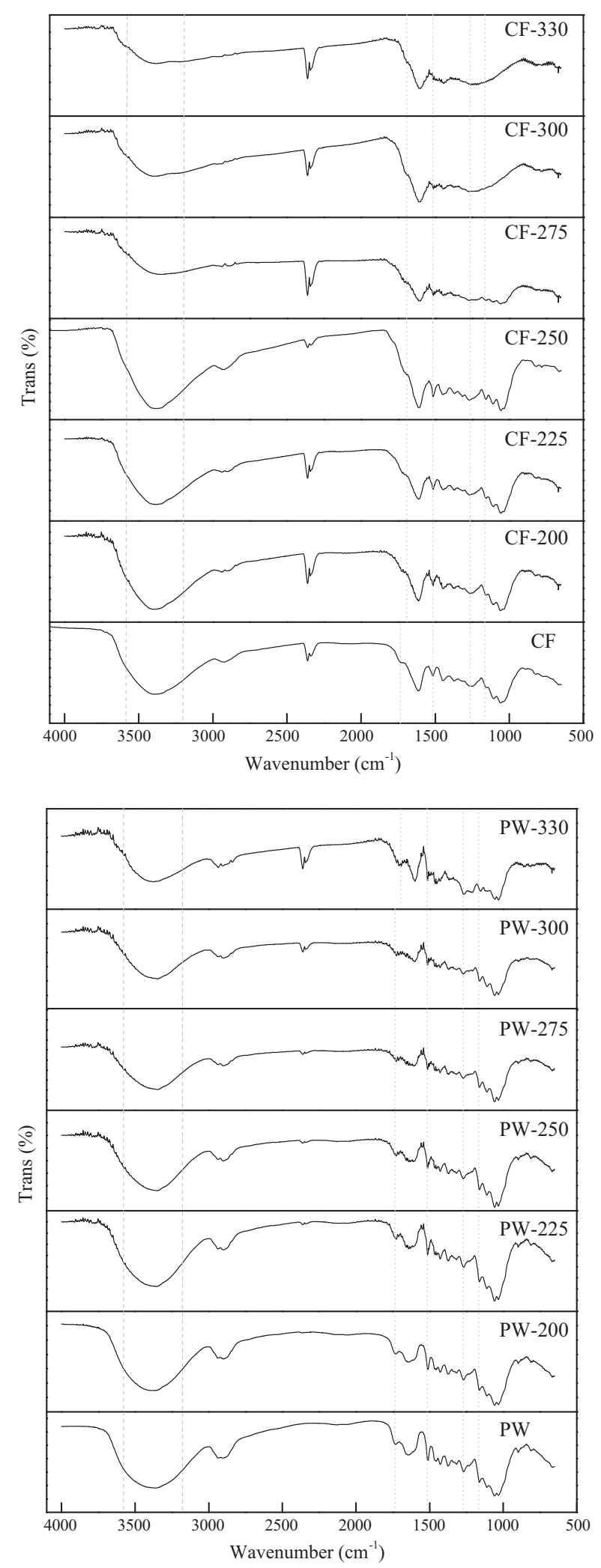

Fig. 6. FT-IR spectra of coconut fiber, pine wood and their derived biochars.

feedstocks due to the high decomposition temperature of cellulose, especially for woody biomass [13].

Compared to raw biomass, improved combustion behaviors of the biochars suggest that increased thermal conversion efficiency and reduced pollutant emissions are expected during biochars combustion. 


\subsection{FT-IR analysis}

FT-IR technique was employed to determine the structural evolution of biomass under pyrolysis conditions. Fig. 6 shows FT-IR spectra of raw biomass and corresponding biochars, with the assignment of the peaks based on IR mentor Pro 2.0 and related publications $[19,24]$. The broad adsorption peak from 3200 to $3600 \mathrm{~cm}^{-1}$ is ascribed to the intra- and inter molecular hydrogen and characteristic peak of crystalline cellulose [25,26]. It can be seen that the intensity of this peak had a significant decrease in both CF and PW after $250^{\circ} \mathrm{C}$ pyrolysis, especially for CF. The peaks around $1734 \mathrm{~cm}^{-1}$ in PW and $1735 \mathrm{~cm}^{-1}$ in CF are attributed to the $\mathrm{C}=\mathrm{O}$ vibration of the carboxylic acids in hemicellulose. This peak disappears in CF-200 and a corresponding new peak appear at $1700 \mathrm{~cm}^{-1}$ is caused by the degradation product of hemicellulose [27]. Different with CF, hemicellulose is still present in the biochar PW-300 and the peak of the corresponding degradation product is around $1698 \mathrm{~cm}^{-1}$. The aromatic $\mathrm{C}-\mathrm{O}$ stretching of methoxyl and phenyl propane structure and aromatic ring vibration in lignin correspond to the peaks at 1231 and $1561 \mathrm{~cm}^{-1}$ in $\mathrm{CF}$, and 1271 and $1517 \mathrm{~cm}^{-1}$ in PW $[28,29]$. There is less change for the intensities of these peaks within the temperature range $200-330^{\circ} \mathrm{C}$ for both $\mathrm{CF}$ and $\mathrm{PW}$, indicating high degradation temperature of the lignin. The peaks caused by the antisymmetric stretching of glycosidic bond of cellulose are around $1162 \mathrm{~cm}^{-1}$ and $1169 \mathrm{~cm}^{-1}$ in CF and PW, respectively. It can be seen that the degradation of cellulose in $\mathrm{CF}$ is more sensitive to pyrolysis temperature than that in PW. The cellulose in $\mathrm{CF}$ is almost totally degraded at temperature higher than $275^{\circ} \mathrm{C}$. While in the case of PW, considerable amount of cellulose is still present at pyrolysis temperature at $330^{\circ} \mathrm{C}$. The higher degradation rate of CF than PW under identical conditions is possibly associated with the catalysis effect of high contents of AAEMs in CF, especially $\mathrm{K}$ [22]. Based on above analysis, it is obvious that same constituent (hemicellulose, cellulose and lignin) of biomass in non-woody and woody biomass shows different decomposition/carbonization temperatures, indicating woody and non-woody biomass have different optimal pyrolysis conditions for solid fuel production.

\section{Conclusions}

Non-woody (Coconut fiber) and woody biomass (pine wood) were upgraded to produce solid fuel biochar by low temperature pyrolysis. The dehydration and decarboxylation reactions of biomass had same preference for the biomass under pyrolysis conditions. All the major ash forming metals were retained in the biochars during biomass pyrolysis. The combustion of the biochars occurred in two temperature zones and the main mass loss shifted to high temperature zone with increasing pyrolysis temperature. Hemicellulose and cellulose in coconut fiber and pine wood showed different decomposition behaviors and consequently significant improvement of combustion performances was observed after $300^{\circ} \mathrm{C}$ pyrolysis for coconut fiber and $330^{\circ} \mathrm{C}$ for pine wood, respectively. The present study shows that low temperature pyrolysis have promising potential to produce solid fuel biochar from waste biomass.

\section{Acknowledgement}

Financial support from the Chinese Academy of Sciences, China is greatly acknowledged.

\section{Appendix A. Supplementary material}

Supplementary data associated with this article can be found, in the online version, at http://dx.doi.org/10.1016/j.fuel.2015.05.032.

\section{References}

[1] Ai-Mansour F, Zuwala J. An overview of biomass co-firing in Europe. Biomass Bioenergy 2010;34:620-9.

[2] Dai J, Sokhansanj S, Grace JR, Bi X, Lim CJ. Overview and some issues related to co-firing biomass and coal. Can J Chem Eng 2008;86:367-86.

[3] Khan AA, Jong W, Jansens PJ, Spliethoff H. Biomass combustion in fluidized bed boilers: potential problems and remedies. Fuel Process Technol 2009;90:21-50.

[4] Mohan D, Pittman CU, Steele P. Pyrolysis of wood/biomass for bio-oil: a critical review. Energy Fuels 2006;20:848-89.

[5] Xiu S, Shahbazi A. Bio-oil production and upgrading research: a review. Renew Sustain Energy Rev 2012;16:4406-14.

[6] Gorling M, Larsson M, Alvfors P. Bio-methane via fast pyrolysis of biomass. Appl Energy 2013;112:440-7.

[7] Richardson Y, Blin J, Julbe A. A short overview on purification and conditioning of syngas produced by biomass gasification; catalytic strategies, process intensification and new concepts. Prog Energy Combust Sci 2012;38:765-81.

[8] Alauddin ZABZ, Lahijani P, Mohammadi M, Mohanmed AR. Gasification of lignocellulosic biomass in fluidized beds for renewable energy development: a review. Renew Sustain Energy Rev 2010;14:2852-62.

[9] Ibrahim RHH, Darvell LI, Jones IM, Williams A. Physicochemical characterisation of torrefied biomass. J Anal Appl Pyrol 2013;103:21-30.

[10] Van der Stelt MJC, Gerhauser H, Kiel JHA, Ptasinski KJ. Biomass upgrading by torrefaction for the production of biofuels: a review. Biomass Bioenergy 2011;35:3748-62.

[11] Arias B, Pevida C, Fermoso J, Plaza MG, Rubiera F, Pis JJ. Influence of torrefaction on the grindability and reactivity of woody biomass. Fuel Process Technol 2008;89:169-75.

[12] Phanphanich M, Mani S. Impact of torrefaction on the grindability and fuel characteristics of forest biomass. Bioresour Technol 2011:102:1246-53.

[13] Park SW, Jang CH, Baek KR, Yang JK. Torrefaction and low-temperature carbonization of woody biomass: evaluation of fuel characteristics of the products. Energy 2012;45:676-85.

[14] Wannapeera J, Worasuwannarak N. Upgrading of woody biomass by torrefaction under pressure. J Anal Appl Pyrol 2012;96:173-80.

[15] Lee JW, Kim YH, Lee SM, Lee HW. Optimizing the torrefaction of mixed softwood by response methodology for biomass upgrading to high energy density. Bioresour Technol 2012;116:471-6.

[16] Wannapeera J, Fungtammasan B, Worasuwannarak N. Effects of temperature and holding time during torrefaction on the pyrolysis behaviors of woody biomass. J Anal Appl Pyrol 2011;92:99-105.

[17] Pentananunt R, Rahman ANMM, Bhattacharya SC. Upgrading of biomass by means of torrefaction. Energy 1990;15:1175-9.

[18] Wahab R, Mohamad A, Samsi HW, Sulaiman O. Effect of heat treatment using palm oil on properties and durability of semantan bamboo. J Bamboo Rattan $2005 ; 4: 211-20$.

[19] Liu Z, Quek A, Kent Hoekman S, Balasubramanian R. Production of solid biochar fuel from waste biomass by hydrothermal carbonization. Fuel 2013;103:943-9.

[20] Okuno T, Somoyama N, Hayshi J, Li C, Sathe C, Chiba T. Primary release of alkali and alkaline earth metallic species during the pyrolysis of pulverized biomass. Energy Fuels 2005;19:2164-71.

[21] Pronobis M. Evaluation of the influence of biomass co-combustion on boiler furnace slagging by means of fusibility correlations. Biomass Bioenergy $2005 ; 28: 375-83$

[22] Saddawi A, Jones JM, Williams A, Coeur CL. Commodity fuels from biomass through pretreatment and torrefaction: effect of mineral content on torrefied fuel characteristics and quality. Energy Fuels 2012;26:6466-74.

[23] Toufiq Reza M, Lynam JG, Helal Uddin M, Corenella CJ. Hydrothermal carbonization: fate of inorganics. Biomass Bioenergy 2013;49:86-94.

[24] Tandy S, Healey JR, Nason MA, Williamson JC, Jones DL, Thain SC. FT-IR as an alternative method for measuring chemical properties during composting. Bioresour Technol 2010;101:5431-6.

[25] Stevanic JS, Salmen L. Characterizing wood polymers in the primary cell wall of Norway spruce (Picea abies (L.) Karst.) using dynamic FT-IR spectroscopy. Cellulose 2008;15:285-95.

[26] Sugiyama J, Persson J, Chanzy H. Combined infrared and electron-diffraction study of the polymorphism of native cellulose. Macromolecules $1991 ; 24: 2461-6$

[27] Gierlinger N, Goswami L, Schmidt M, Burgert I, Coutand C, Rogge T, et al. In situ FT-IR microscopic study on enzymatic treatment of poplar wood crosssections. Biomacromolecules 2008;9:2194-201.

[28] Akerholm M, Salmen L. The oriented structure of lignin and its viscoelastic properties studied by static and dynamic FTIR spectroscopy. Holzforschung 2003;57:459-65.

[29] Agarwal UP, Ralph SA. FT-Raman spectroscopy of wood: identifying contributions of lignin and carbohydrate polymers in the spectrum of black spruce (Picea mariana). Appl Spectrosc 1997;51:1648-55. 